\title{
The clinical efficiency of acupuncture in preventing migraine attacks and its effect on serotonin levels
}

\section{Akupunturun migren ataklarının önlenmesinde klinik etkinliği ve serotonin düzeylerine etkisi}

\author{
Mualla Biçer, ${ }^{1}$ Dilek Bozkurt, ${ }^{2}$ Murat Çabalar, ${ }^{2}$ Nilgün Işıksaçan, ${ }^{3}$ Asuman Gedikbaşıs, ${ }^{3}$ Arsida Bajrami, ${ }^{2}$ İlknur Aktaşs \\ ${ }^{1}$ Department of Physical Therapy and Rehabilitation, Bakırköy Dr. Sadi Konuk Training and Research Hospital, İstanbul, Turkey \\ ${ }^{2}$ Department of Neurology, Bakırköy Dr. Sadi Konuk Training and Research Hospital, İstanbul, Turkey \\ ${ }^{3}$ Department of Biochemistry, Bakırköy Dr. Sadi Konuk Training and Research Hospital, İstanbul, Turkey \\ ${ }^{4}$ Department of Physical Therapy and Rehabilitation, Fatih Sultan Mehmet Training and Research Hospital, İstanbul, Turkey
}

Received / Geliş tarihi: December 2015 Accepted / Kabul tarihi: March 2016

\begin{abstract}
Objectives: This study aims to investigate the efficacy of acupuncture in preventing migraine attacks.

Patients and methods: Between December 2013 and June 2014, a total of 54 patients with a diagnosis of migraine in our neurology clinic were randomized into two groups. Venlafaxine was administered for three months to one group (drug therapy group: 4 males, 21 females; mean age 32.0 \pm 9.1 years; range, 18 to 65 years), while the other group was treated with acupuncture (acupuncture group: 5 males, 24 females; mean age $30.3 \pm 7.4$ years; range, 18 to 65 years). The control group consisted of a total of 29 healthy individuals (7 males, 22 females; mean age $30.3 \pm 7.4$ years; range 18 to 65 years). Blood serotonin levels were assessed before and after treatment along with visual analog scale (VAS) and Migraine Disability Assessment (MIDAS) in both groups.

Results: There was no statistically significant difference in the mean analgesic use before and after the treatment and VAS and MIDAS scores between the acupuncture and drug therapy groups ( $>0.05)$. The number and duration of attacks was found to be significantly lower in both groups, compared to the pre-treatment values $(\mathrm{p}<0.0001)$. The serotonin levels in the acupuncture and drug therapy groups were significantly higher compared to the pre-treatment values $(\mathrm{p}<0.001)$. Serotonin levels were found to be significantly lower in healthy individuals compared to the study groups $(\mathrm{p}<0.0001)$.
\end{abstract}

Conclusion: Based on our study findings, acupuncture may be an effective option in the migraine prophylaxis.

Keywords: Acupuncture; migraine; serotonin.

\section{$\ddot{O Z Z}$}

Amaç: Bu çalışmada akupunkturun migren ataklarının önlenmesindeki etkinliği araştırıldı.

Hastalar ve yöntemler: Aralık 2013 - Haziran 2014 tarihleri arasında nöroloji kliniğimizde migren tanısını konan toplam 54 hasta rasgele iki gruba ayrıldı. Bir gruba (ilaç tedavisi grubu: 4 erkek, 21 kadın; ort. yaş 32.0 \pm 9.1 yıl; dağılım 18-65 yıl) üç ay süreyle venlafaksin uygulanırken,

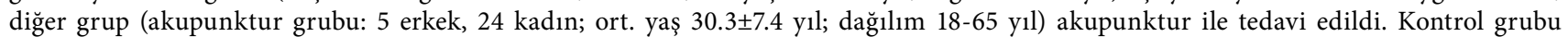

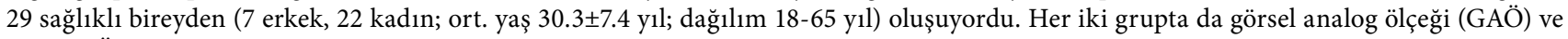
Migren Özürlülük Değerlendirmesi (MIDAS) ile birlikte tedavi öncesi ve sonrası kan serotonin düzeyleri ölçüldü.

Bulgular: Akupunktur ve ilaç grubu arasında tedavi öncesi ve sonrası ortalama analjezik ilaç kullanımı ve GAÖ ve MIDAS skorları açısından istatistiksel olarak anlamlı fark saptanmadı ( $>0.05)$. Atak sayı ve süresi, her iki grupta da tedavi öncesi değerlere kıyasla, anlamlı düzeyde düşük bulundu $(\mathrm{p}<0.0001)$. Akupunktur ve ilaç grubunda serotonin düzeyleri, tedavi öncesi değerlere kıyasla, anlamlı düzeyde yüksekti $(\mathrm{p}<0.0001)$. Çalışma gruplarına kıyasla, sağlıklı bireylerin serotonin düzeyleri, anlamlı düzeyde düşük bulundu $(\mathrm{p}<0.0001)$.

Sonuç: Çalışma bulgularımıza göre, akupunktur, migren profilaksisinde etkili bir seçenek olabilir.

Anahtar sözcïkler: Akupunktur; migren; serotonin.

Corresponding author / İletişim adresi: Nilgün Işıksaçan, MD. Bakırköy Dr. Sadi Konuk Eğitim ve Araştırma Hastanesi, Biyokimya Bölümü, 34147 Bakırköy, İstanbul, Turkey. e-mail / e-posta: nisiksacan@gmail.com 
Migraine is a headache disorder characterized by recurrent attacks. Prophylactic treatment constitutes an important aspect of migraine management. Migraine often affects social and work life, leading to excessive use of analgesics. Prophylactic treatment is predominantly used to reduce frequency, duration and severity of attacks. It reduces the utilization of acute treatment improving the patient's functional state. Furthermore, it may prevent transformation of episodic migraine to chronic migraine and reduce health expenditures. ${ }^{[1]}$ Neurovascular, biochemical and thrombolytic theories have been proposed as implicated in the pathogenesis of migraine attacks. ${ }^{[2,3]}$ Acupuncture, widely used in Eastern countries, is recently gaining popularity in Western countries. Acupuncture has a long history of use in the treatment of many pain conditions, including headache. ${ }^{[4]}$ Acupuncture stimulation causes a release of endorphins, serotonin, enkephalins, gammaaminobutyric acid, norepinephrine and dopamine which help explain the effect of acupuncture on a biomedical and pharmacological basis. ${ }^{[4,5]}$

The purpose of this study is to measure serotonin levels in blood after acupuncture treatment in migraine patients and investigate the efficacy of acupuncture in the prophylaxis of migraine.

\section{PATIENTS AND METHODS}

A total of 250 patients who received a diagnosis of migraines from the Neurology outpatient clinic at our hospital were enrolled in the study. Fifty-four patients who fulfilled the inclusion criteria and completed the follow-up visits were eligible for the study.

A total of 54 migraine patients, who consulted at the Neurology Outpatient Clinic of Bakirkoy Dr. Sadi Konuk Education and Research Hospital between December 2013 and June 2014 and were diagnosed as migraine according to the diagnostic criteria of the International Headache Society (IHS) (2004) were evaluated. Patients fitting the inclusion criteria were enrolled in the study. The inclusion criteria were as follows: both male and female gender, age between 18 and 65 years, migraine diagnosis for more than two years, the presence of migraine attacks before the age of 50 and having four or more attacks within the past three months.

Ethics committee approval was obtained by the Ethics Board of Bakirkoy Dr. Sadi Konuk Education and Research Hospital (Date: 14.07.2014 Resolution No. 2014-09-14). The study was conducted in accordance with the principles of the Declaration of Helsinki.
Patients who accepted to participate, were enrolled in the study after signed informed consent was obtained, and were randomized to drug treatment group (4 males, 21 females; mean age 32.0 49.1 years; range 18 to 65 years) and acupuncture group (5 males, 24 females; mean age $33.76 \pm 7.82$ years; range 18 to 65 years) using a computer-generated, random block design. Twenty-nine age- and sex-matched healthy subjects ( 7 males, 22 females; mean age $30.3 \pm 7.4$ years; range 18 to 65 years) were admitted to study, who received no treatment (Figure 1).

Among these patients, 25 were treated with venlafaxine $75-225 \mathrm{mg} /$ day for a period of three months. Patients suffering from other types of headache (tension type, cluster and secondary headache) or other neurological diseases; for example, patients with chronic disorders such as hypertension, diabetes mellitus, chronic obstructive pulmonary disease, asthma, coronary artery disease and liver disease were excluded from the study. Also, patients who were pregnant, using insufficient contraception, history of antipsychotic agents or antidepressants use within the last three months, patients suffering from painful periods longer than 15 days a month and history of excessive use of drugs or alcohol abuse or history of head trauma were excluded from the study.

Pre-treatment and post-treatment headache frequency and duration, analgesic drug and triptan usage were evaluated using visual analog scale (VAS) and Migraine Disability Assessment (MIDAS). ${ }^{[6]}$ Demographic and clinical characteristics of the patients were recorded prior to the treatment. The acupuncture treatment was administered in a total of 26 sessions, first three days a week (12 sessions), then two days a week. The

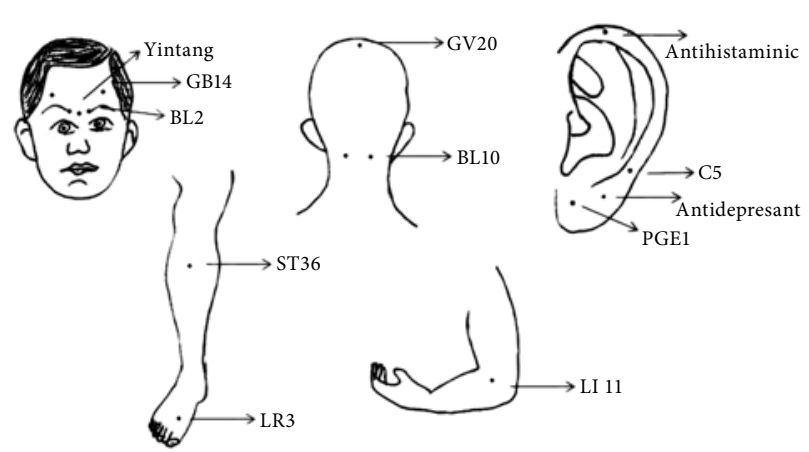

Figure 1. Randomized clinical trial comparing acupuncture with drug therapy for migraine (CONSORT diagram). Participants with migraine were randomized to receive either acupuncture $(n=29)$ or drug therapy $(n=25)$. GB14: Gall Bladder14; BL2: Bladder2; ST36: Stomach36; LR3: Liver 3; GV20: Governing Vessel20; BL10: Bladder 10; PGE1: ProstaglandinE1; LI 11: Large Intestine 11. 
acupoints were selected in accordance with the related literature and textbooks. ${ }^{[7,8]}$ All acupuncture points were prepared with $70 \%$ alcohol pads with participants in a resting position appropriate for the manipulation of the selected acupoints. Acupuncture procedures were performed by an experienced acupuncturist, using two disposable stainless steel needles $(0.3 \mathrm{~mm}$ diameter, $25 \mathrm{~mm}$ length, Suzhou Jiangsu, China) that were inserted to a depth of $0.3-1 \mathrm{~cm}$ according to TCM standards. The sensation of ache or heaviness in the area surrounding the inserted needle (known as "De qi") was always achieved. Treatments lasted 30 minutes and the last 15 minutes were performed by rotating the needle in all of the patients in order to achieve "De qi". Both ear and body acupuncture was performed. The points used were Governing Vessel20 (GV20), Gall Bladder14 (GB14) (x2), Bladder2 (BL2) (x2), BL10 (x2) Yintang in the head; the dominant side of the ear, cervical (C) vertebra $\mathrm{C} 5$, antidepression, prostaglandin E1 (PGE1), and body points were Large Intestine4 (Li4) (x2), Li 11 (x2), Stomach36 (ST36) (x2), Liver 3 (Liv3) (x2) (Figure 2).
Serotonin levels were measured in both groups. Fasting venous blood samples were collected by venipuncture into K3 EDTA vacationer tubes (BD). Ten milligram EDTA and $75 \mathrm{mg}$ ascorbic acid was added to all samples and immediately centrifuged at $150 \mathrm{~g}$ for 20 minutes. Platelet-rich plasma was separated and frozen at $-80{ }^{\circ} \mathrm{C}$ until analyses. Serotonin measurements were performed with a microELISA method using a DMN 9602G microELISA microplate reader (Geeing Biotechnology Co., Ltd. China) according to the instruction manual. Blood samples were taken before acupuncture and three months after therapy. All patients were put on a tryptophan restricted diet (poor of bananas, prunes, walnuts, and coffee) and medications that could affect tryptophan levels such as, acetaminophen, catecholamines and reserpine group of drugs for a period of one week before blood collections. In this randomized, controlled, prospective study, patients were informed about side effects of the drug and acupuncture.

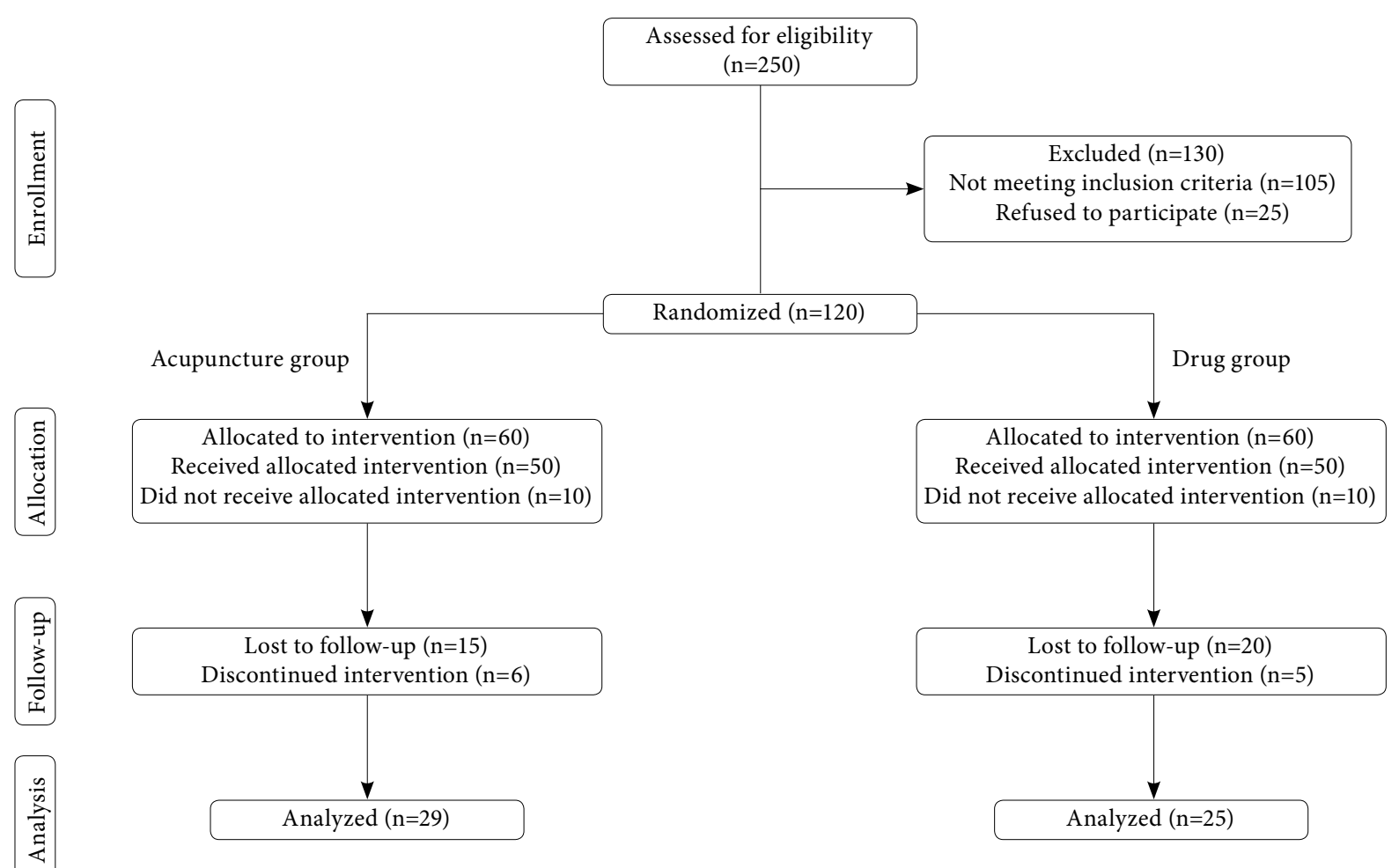

Figure 2. Applied acupuncture points: Antihistaminic, C5, PGE1, and antidepression points in the ear; BL2, at the medial end of the eyebrow; BL10, under the external occipital protuberance, 1.3 cun of the lateral; GB14, on the forehead, along the vertical line of the pupil when looking straight ahead; GV20, on the sagittal axis cephalic; LI4, at the midpoint of the second metacarpal bone; LI 11-midway between the lateral side of the transverse crease of the elbow and the epicondyle of the humerus; ST36; edge of tibia; LR3; On the dorsum of foot; between the heads of the first and second metatarsal bones; Yintang; Extraordinary point. C5: Cervical 5; PGE1: ProstaglandinE1; BL2: Bladder2; GB14: Gall Bladder14; GV20: Governing Vessel20; LI4: Large Intestine4; ST 36: Stomach36. 


\section{Statistical analysis}

Statistical analysis was performed using the SPSS for Windows version 11.5 software (SPSS Inc., Chicago, IL, USA). Mean, standard deviation, frequency and percentage values were used in the given descriptive statistics of the data. The distribution of the variables was measured with Kolmogorov-Smirnov test. ANOVA (Turkey test) and independent sample $t$-test were used for the analysis of quantitative data. Paired samples t-test was used in the analyses of the repeated measures. Chi-square test was used for the analysis of qualitative data and Fisher's exact test was used when chi-square test conditions were not met. The results were evaluated in $95 \%$ confidence interval, where $\mathrm{p}<0.05$.

\section{RESULTS}

Age, sex and education levels between the two groups were similar (Table 1). Aura was present in 14 patients (48.28\%) in the acupuncture group, and in 11 in the drug treatment group $(\mathrm{p}=0.753)$. Unilateral headache was present in 21 patients in the acupuncture group (72.41\%) and 22 patients in the drug treatment group $(88 \%)$, respectively $(\mathrm{p}=0.156)$. Photophobia was also present in 27 patients (93.10\%) in the acupuncture group and 25 patients in the drug treatment group $(100 \%)$, respectively $(\mathrm{p}=0.181)$. Photophobia in the acupuncture group was present in 26 patients $(89.66 \%)$ and in the drug treatment group in 22 patients $(88 \%)(\mathrm{p}=0.847)$. Allodynia was present in 21 patients in the acupuncture group (72.41\%) and in 16 patients in the drug treatment group (64\%), respectively $(\mathrm{p}=0.507)$.

No statistically significant difference was observed between acupuncture and drug therapy groups in mean analgesic drug usage and VAS and MIDAS values before the study $(p>0.05)$. Significantly lower mean analgesic use during study was found in both the acupuncture and the drug treatment groups when compared to the same duration before study $(\mathrm{p}<0.001$ and $\mathrm{p}<0.001$, respectively). The number and duration of attacks was found to be significantly lower $(\mathrm{p}<0.001)$ in the acupuncture and drug treatment groups compared to the values obtained before treatment. Also significantly lower mean VAS values were observed after therapy when compared to values before therapy in the acupuncture and the drug treatment groups, $(\mathrm{p}<0.001$ and $\mathrm{p}<0.001$, respectively). Similarly, mean MIDAS values were found to be significantly lower after therapy in comparison to before therapy in the acupuncture and the drug treatment groups $(\mathrm{p}<0.001$ and $\mathrm{p} \leq 0.001$, respectively) (Table 2). The mean serotonin values after treatment of the control group $(378.52 \pm 67.40 \mathrm{ng} / \mathrm{mL})$ were found to be statistically higher $(\mathrm{p}<0.001)$ when compared to the acupuncture $(314.3 \pm 51.54 \mathrm{ng} / \mathrm{mL})$ and the drug treatment group $(257.19 \pm 12.62 \mathrm{ng} / \mathrm{mL})$. Serotonin levels in the acupuncture and the drug treatment group were found to be significantly higher than the levels measured before treatment $(\mathrm{p}<0.001)$ (Table 3$)$.

\section{DISCUSSION}

Migraine is a chronic neurological disorder, characterized by mild to severe pulsating headache attacks, often on one side of the head. Diagnosis criteria have been determined by HIS. Migraine is probably 2-3 times more prevalent in women, possibly due to genetic and hormonal reasons. It is classified into two categories as migraine with and without aura. Migraine without aura accounts for approximately $90 \%$ of all migraine cases. ${ }^{[9]}$ Based on the pathophysiology of migraine, it is believed that the neurotransmitter serotonin $(5-\mathrm{HT})$ is involved in the initiation of the pain in migraine. The biochemical theory depends on a decrease of serotonin level in blood and increase of 5-hydroxyindolaceticacid (5-HIAA), a metabolite shown in urine during an attack. ${ }^{[10]}$ The effects on migraine exhibited by medicines such as selective serotonin reuptake inhibitors (SSRI) and serotonin receptor antagonists that affect central serotonin transmission are evidence that supports this biochemical theory. ${ }^{[1]}$ In a recent study the effectiveness of a serotonin and noradrenaline reuptake inhibitor (SNRI) such as

Table 1. Patients' demographic features

\begin{tabular}{|c|c|c|c|c|c|c|c|c|c|c|}
\hline & \multicolumn{3}{|c|}{ Control group } & \multicolumn{3}{|c|}{ Acupuncture group } & \multicolumn{3}{|c|}{ Drug group } & \multirow[b]{2}{*}{$p$} \\
\hline & $\mathrm{n}$ & $\%$ & Mean \pm SD & $\mathrm{n}$ & $\%$ & Mean \pm SD & $\mathrm{n}$ & $\%$ & Mean \pm SD & \\
\hline Age (years) & & & $30.31 \pm 7.4$ & & & $33.76 \pm 7.82$ & & & $32.04 \pm 9.13$ & 0.274 \\
\hline Sex & & & & & & & & & & 0.708 \\
\hline Female & 22 & 75.90 & & 24 & 82.80 & & 21 & 84 & & \\
\hline Male & 7 & 24.10 & & 5 & 17.20 & & 4 & 16 & & \\
\hline
\end{tabular}


Table 2. Clinical characteristics of the patients before and after treatment

\begin{tabular}{|c|c|c|c|c|c|}
\hline & \multicolumn{2}{|c|}{ Acupuncture group } & \multicolumn{2}{|c|}{ Drug group } & \multirow[b]{2}{*}{$p$} \\
\hline & Mean \pm SD & $p$ & Mean \pm SD & $p$ & \\
\hline \multicolumn{6}{|c|}{ Number of attacks (month) } \\
\hline Before treatment & $5.31 \pm 1.67$ & & $6.2 \pm 2.2$ & & $=0.098$ \\
\hline After treatment & $2.07 \pm 1.46$ & & $1.8 \pm 1.41$ & & $=0.497$ \\
\hline$p$ & & $<0.001$ & & $<0.001$ & \\
\hline \multicolumn{6}{|l|}{ Attack length (hour) } \\
\hline Before treatment & $26.48 \pm 17.56$ & & $20.96 \pm 13.46$ & & $=0.206$ \\
\hline After treatment & $9.39 \pm 11.3$ & & $6.28 \pm 7.26$ & & $=0.245$ \\
\hline$p$ & & $<0.001$ & & $<0.001$ & \\
\hline \multicolumn{6}{|c|}{ Days with headache (month) } \\
\hline Before treatment & $6.86 \pm 2.33$ & & $6.88 \pm 1.94$ & & $=0.976$ \\
\hline After treatment & $2.32 \pm 1.79$ & & $1.8 \pm 1.41$ & & $=0.248$ \\
\hline$p$ & & $<0.001$ & & $<0.001$ & \\
\hline \multicolumn{6}{|c|}{ Number of analgesic (month) } \\
\hline Before treatment & $7.03 \pm 3.18$ & & $5.64 \pm 3.15$ & & $=0.112$ \\
\hline After treatment & $1.93 \pm 1.72$ & & $1.44 \pm 1.29$ & & $=0.252$ \\
\hline$p$ & & $<0.001$ & & $<0.001$ & \\
\hline \multicolumn{6}{|c|}{ Triptan number (month) } \\
\hline Before treatment & $1.72 \pm 2.15$ & & $1.4 \pm 2.35$ & & $=0.599$ \\
\hline After treatment & $0.39 \pm 0.96$ & & $0.48 \pm 1.3$ & & $=0.780$ \\
\hline$p$ & & $<0.001$ & & $=0.015$ & \\
\hline \multicolumn{6}{|l|}{ Visual analog scale } \\
\hline Before treatment & $9.1 \pm 0.9$ & & $8.88 \pm 1.05$ & & $=0.404$ \\
\hline After treatment & $5.75 \pm 2.03$ & & $4.64 \pm 2.56$ & & $=0.085$ \\
\hline$p$ & & $<0.001$ & & $<0.001$ & \\
\hline \multicolumn{6}{|c|}{ Migraine disability assessment } \\
\hline Before treatment & $44.62 \pm 17.21$ & & $42.84 \pm 15.35$ & & $=0.692$ \\
\hline After treatment & $8.82 \pm 12.4$ & & $7.04 \pm 8.57$ & & $=0.550$ \\
\hline$p$ & & $<0.001$ & & $<0.001$ & \\
\hline
\end{tabular}

SD: Standard deviation.

venlafaxine in migraine prophylaxis was compared to placebo. This prospective study included a total of 60 patients with migraine without aura that were given $75-150 \mathrm{mg}$ of venlafaxine or placebo randomly. Two months later the effectiveness was evaluated. The results of the study indicated that venlafaxine was more effective compared to placebo in migraine prophylaxis and considered a well-tolerated drug. ${ }^{[12]}$
In another study conducted to investigate the effectiveness of venlafaxine and amitriptyline in migraine prophylaxis, both were found to be significantly effective in reducing pain parameters but the side effect profile of venlafaxine was found superior when compared to that of amitriptyline. ${ }^{[13]}$ Similar to the results of this study, our study recorded a decrease in pain intensity, frequency and duration

Table 3. Serotonin levels in the group before and after treatment

\begin{tabular}{|c|c|c|c|c|}
\hline \multirow[t]{2}{*}{ Tukey multiple comparison test } & \multicolumn{2}{|c|}{$\begin{array}{c}\text { Serotonin levels }(\mathrm{ng} / \mathrm{mL}) \\
\text { Pre-treatment }\end{array}$} & \multicolumn{2}{|c|}{$\begin{array}{l}\text { Serotonin levels }(\mathrm{ng} / \mathrm{mL}) \\
\text { Post-treatment }\end{array}$} \\
\hline & Mean \pm SD & $p$ & Mean \pm SD & $p$ \\
\hline Control group & $378.52 \pm 67.40$ & & $378.52 \pm 67.40$ & \\
\hline Acupuncture group & $314.3 \pm 51.54$ & & $314.3 \pm 51.54$ & \\
\hline$p$ & & $<0.001$ & & $<0.001$ \\
\hline Control group & $378.52 \pm 67.40$ & & $378.52 \pm 67.40$ & \\
\hline Drug group & $292.96 \pm 36.31$ & & $257.19 \pm 12.62$ & \\
\hline$p$ & & $<0.001$ & & $<0.001$ \\
\hline Acupuncture group & $292.96 \pm 36.31$ & & $314.3 \pm 51.54$ & \\
\hline Drug group & $247.14 \pm 13.81$ & & $257.19 \pm 12.62$ & \\
\hline$p$ & & 0.906 & & $<0.001$ \\
\hline
\end{tabular}


after venlafaxine intake (75-225 $\mathrm{mg} /$ day). In addition to the design of the previous studies which included only drug administration, we added the acupuncture group. We compared the effects of both applications upon blood serotonin levels.

Acupuncture is one of the oldest standardized neuromodulatory treatment modalities of traditional Chinese medicine. It is increasingly being adopted in the West as a complementary and alternative treatment to prevent migraine attacks and to relieve pain during migraine. ${ }^{[14]}$ Acupuncture treatment involves the insertion of fine, single-use, sterile needles in acupoints according to a system of channels and meridians. The needles are stimulated by manual manipulation, electrical stimulation or heat. The general theory of acupuncture is based on the premise that there are patterns of energy flow (Qi) through the body that are essential for health. Disruptions of this flow are believed to be responsible for disease. ${ }^{[15]}$ The immersion of the acupuncture needle results in the release of endogenous opioids by stimulating the free nerve endings of pain receptors known to be involved in pain control. Neurotransmitters involved in the analgesic system such as beta-endorphin, serotonin and enkephalin play an important role in this mechanism. ${ }^{[16]}$

The possibility that acupuncture affects the reward system pathway of the brain by activation of serotoninergic neurons has been suggested by several authors. The latest Cochrane meta-analysis suggests that acupuncture as a migraine prophylaxis is safe and at least as effective, if not more effective than prophylactic drug treatment. ${ }^{[17]}$ Acupuncture's efficiency as a treatment modality has been accepted by the World Health Organization too.

In 22 meta-analysis, a total of 4,419 patients were examined; in six of the studies, 3-4 months of acupuncture have shown to be effective in the treatment of migraine attacks, in 14 studies real and sham acupuncture were compared and acupuncture was found to be the more effective of the two, but in both cases, headache frequency decreased after treatment, in the remaining four studies drug therapy was compared to acupuncture and acupuncture was found to be more effective and to have less side effects than drug therapy. ${ }^{[18]}$

In two large studies acupuncture treatment was found to be statistically significantly effective in terms of reducing the number of headache days and pain severity in the short-term (three months). ${ }^{[4]}$
In a study related to migraine, acupuncture and prophylactic drug treatment were compared. A decrease in pain score, increase in serotonin levels and fewer side effects were observed in the acupuncture group. ${ }^{[4]}$ In another remarkable study, acupuncture and valproate treatment were compared and in the group treated with valproate pain severity was decreased and in the acupuncture group no side effect were observed. ${ }^{[19]}$

Therefore, acupuncture therapy seems to have independent therapeutic effects superior to sham acupuncture, particularly in term of pain relief. There is significant evidence of acupuncture's value, which will expand its use into conventional medicine and encourage further studies of its physiology and clinical value. The treatment process with acupuncture and its efficacy in the short-term after treatment are well known. Long-term effects of treatment need further studies.

The treatment protocol that we applied in our study led to a decrease in the number of migraine attacks, mean attack duration, number of headache days within a month, drug consumption, decrease in VAS, MIDAS values, increase in blood serotonin level. Although, there was no difference in terms of efficacy between the two groups, given the cost and drug side effects of the medications, we think acupuncture is a good alternative treatment.

Studies on the effect of acupuncture on serotonin levels in the treatment of migraine are limited. Two new studies investigating the blood serotonin level in treatment of migraine with acupuncture indicated high serotonin levels. Changes in blood serotonin levels in patients with migraine headaches before and after a course of reflexotherapy. ${ }^{[20]}$

In another study the use of antidepressants in the treatment of chronic migraine was not associated with changes in serotonin levels, but it has been shown to be more effective in the management of acute pain. ${ }^{[21]}$ To date there is no such data for venlafaxine.

In our study, the serotonin levels of the control group was significantly higher before and after treatment in both the acupuncture and the medication groups.

In conclusion, our study has shown us that, acupuncture is a reliable, inexpensive alternative treatment to venfloxasin in terms of decreasing severity, duration of pain and number of attacks. Long-term studies that include a larger group of 
patients are needed to answer the question of whether acupuncture can be an alternative to drug therapy.

\section{Declaration of conflicting interests}

The authors declared no conflicts of interest with respect to the authorship and/or publication of this article.

\section{Funding}

The authors received no financial support for the research and/or authorship of this article.

\section{REFERENCES}

1. Buse DC, Rupnow MF, Lipton RB. Assessing and managing all aspects of migraine: migraine attacks, migraine-related functional impairment, common comorbidities, and quality of life. Mayo Clin Proc 2009;84:422-35.

2. Saengjaroentham C, Supornsilpchai W, Ji-Au W, Srikiatkhachorn A, Maneesri-le Grand S. Serotonin depletion can enhance the cerebrovascular responses induced by cortical spreading depression via the nitric oxide pathway. Int J Neurosci 2015;125:130-9.

3. Danese E, Montagnana M, Lippi G. Platelets and migraine. Thromb Res 2014;134:17-22.

4. Schiapparelli P, Allais G, Rolando S, Airola G, Borgogno $P$, Terzi MG, et al. Acupuncture in primary headache treatment. Neurol Sci 2011;32:15-8.

5. Lu DP, Lu GP. An Historical Review and Perspective on the Impact of Acupuncture on U.S. Medicine and Society. Med Acupunct 2013;25:311-6.

6. Stewart WF, Lipton RB, Whyte J, Dowson A, Kolodner $\mathrm{K}$, Liberman JN, et al. An international study to assess reliability of the Migraine Disability Assessment (MIDAS) score. Neurology 1999;53:988-94.

7. Li Y, Liang F, Yu S, Liu X, Tang Y, Yang X, et al. Randomized controlled trial to treat migraine with acupuncture: design and protocol. Trials 2008;9:57.

8. Zhang Y, Wang L, Liu H, Li N, Li J, Yi J. The design and protocol of acupuncture for migraine prophylaxis: a multicenter randomized controlled trial. Trials 2009;10:25.

9. He Y, Li Y, Nie Z. Typical aura without headache: a case report and review of the literature. J Med Case Rep 2015;9:40.
10. D’Andrea G, D’Amico D, Bussone G, Bolner A, Aguggia M, Saracco MG, et al. Tryptamine levels are low in plasma of chronic migraine and chronic tension-type headache. Neurol Sci 2014;35:1941-5.

11. Reddy DS. The pathophysiological and pharmacological basis of current drug treatment of migraine headache. Expert Rev Clin Pharmacol 2013;6:271-88.

12. Ozyalcin SN, Talu GK, Kiziltan E, Yucel B, Ertas M, Disci $R$. The efficacy and safety of venlafaxine in the prophylaxis of migraine. Headache 2005;45:144-52.

13. Bulut S, Berilgen MS, Baran A, Tekatas A, Atmaca M, Mungen B. Venlafaxine versus amitriptyline in the prophylactic treatment of migraine: randomized, double-blind, crossover study. Clin Neurol Neurosurg 2004;107:44-8.

14. Cui Y, Shu XO, Gao Y, Wen W, Ruan ZX, Jin F, et al. Use of complementary and alternative medicine by chinese women with breast cancer. Breast Cancer Res Treat 2004;85:263-70.

15. Sahin S, Bicer M, Eren GA, Tas S, Tugcu Tasci AI, et al. Acupuncture relieves symptoms in chronic prostatitis/chronic pelvic pain syndrome: a randomized, sham-controlled trial. Prostate Cancer Prostatic Dis 2015;18:249-54.

16. Chen Z, Hedner J, Hedner T. Substance P-induced respiratory excitation is blunted by delta-receptor specific opioids in the rat medulla oblongata. Acta Physiol Scand 1996;157:165-73.

17. Linde K, Allais G, Brinkhaus B, Manheimer E, Vickers A, White AR. Acupuncture for migraine prophylaxis. Cochrane Database Syst Rev 2009;1:001218.

18. Da Silva AN. Acupuncture for migraine prevention. Headache 2015;55:470-3.

19. Facco E, Liguori A, Petti F, Fauci AJ, Cavallin F, Zanette G. Acupuncture versus valproic acid in the prophylaxis of migraine without aura: a prospective controlled study. Minerva Anestesiol 2013;79:634-42.

20. Jia CS, Zheng LY, Shi J, Ma XS, Li XF, Li WL, et al. Effect of otopoint-needle embedment on headache and plasma 5-HT content in migraine patients. Zhen Ci Yan Jiu 2010;35:44852. [Abstract]

21. Karpa KD, Cavanaugh JE, Lakoski JM. Duloxetine pharmacology: profile of a dual monoamine modulator. CNS Drug Rev 2002;8:361-76. 